Психология. Журнал Высшей школы экономики,

2020. T. 17. № 2. C. 191-209. DOI: 10.17323/1813-8918-2020-2-191-209

\title{
ПСИХОМЕТРИЧЕСКИЙ АНАЛИЗ НОВОЙ ШКАЛЫ АПАТИИ
}

\begin{abstract}
А.А. ЗОЛОТАРЕВА
${ }^{a}$ Национальный исследовательский университет «Высшая школа экономики», 101000, Россия, Москва, ул. Мясницкая, д. 20

\section{Резюме}

В статье представлены результаты разработки и психометрического анализа новой психологической Шкалы апатии. В трех сериях исследования, в которых в общей сложности приняли участие 727 взрослых русскоязычных респондентов, получены убедительные доказательства психометрической состоятельности шкалы. В первой серии исследования была произведена предварительная апробация Шкалы апатии, которая указала на гомогенную и воспроизводимую факторную структуру шкалы. Во второй серии исследования была оценена надежность и валидность Шкалы апатии. Коэффициент $\alpha$ Кронбаха -0.85 , а различия между средними значениями апатии, измеренными во время теста и ретеста, оказались статистически не значимыми по графику Бланда-Альтмана. Конвергентная и дивергентная валидность шкалы была установлена посредством прямых связей шкалы с показателями юношеской апатии, отчужденности от учебы, академической амотивации, алекситимии и социальной ангедонии, а также обратных связей с показателями увлеченности учебой, познавательной мотивации, мотивации достижения, мотивации саморазвития, самоуважения, интроецированной и экстернальной мотивации. В третьей серии исследования была произведена оценка социальной желательности Шкалы апатии. С помощью экспериментальной манипуляции с fake-good, стандартной и fake-bad инструкциями, а также анализа корреляционных связей шкалы с Опросником социальной желательности Д. Паулуса было показано, что шкала устойчива и адекватна в условиях высокой социальной желательности. На основании результатов исследования делается вывод о том, что новая психологическая Шкала апатии является надежным и валидным инструментом для психологической диагностики апатии у взрослых русскоязычных респондентов.
\end{abstract}

Ключевые слова: апатия, Шкала апатии, факторная структура, надежность, валидность, социальная желательность.

Термин «апатия», по данным PsychPro® (базы данных Американской психиатрической ассоциации), встречается практически в трех тысячах работ по психиатрии, среди которых больше трети - статьи, посвященные проблеме диагностики апатии. За более чем вековую историю исследований психиатры создали свыше полутора десятка клинических шкал апатии (Clarke et al., 2011). Для

Исследование поддержано грантом Президента Российской Федерации для государственной поддержки молодых российских ученых - кандидатов наук (проект № МК-541.2020.6). 
сравнения, согласно данным PsycINFO® (базы данных Американской психологической ассоциации), термин «апатия» упоминается лишь в 117 работах по психологии, причем среди них всего лишь одна публикация описывает попытку ее психологической диагностики (Handelman, 1999). Данная статистика вполне объяснима в силу того, что проблема апатии возникла и получила интенсивное развитие именно в психиатрии, однако в последние годы сами психиатры говорят о необходимости привлечения психологов к решению ряда задач, связанных с диагностикой, превенцией и интервенцией апатии.

В развитии проблемы апатии можно выделить три основных периода, в рамках которых в психиатрии сложились разные традиции ее диагностики.

Первый период пришелся на 1900-1990-е гг. Термин «апатия» (от греч. $\alpha \pi \alpha \dot{\theta} \varepsilon \iota \alpha-$ бесчувственность) впервые был употреблен в научной литературе в 1902 г. французским психиатром Р. Масселоном (Masselon, 1902). Вслед за ним при описании психического статуса пациентов с кататоническим синдромом психиатры стали повсеместно использовать понятие «апатия». Так, Э. Крепелин включил кататонию в dementia praecox, или раннее слабоумие, к основным проявлениям которого отнес нарастающую апатию, ослабление разума и поражение чувств и воли больного (Kraepelin, 1919). Его коллега Э. Блейлер также писал о том, что dementia praecox (позже названная шизофренией) характеризуется оскудением эмоций и снижением продуктивности с последующей утратой инициативности и какой-либо целенаправленной деятельности, вследствие чего больные с таким диагнозом впадают в состояние апатии, похожее на «спокойствие могилы» (Bleuler, 1911).

Тем самым основной характеристикой первого периода является отношение к апатии как к потере эмоциональной чувствительности при шизофрении. Именно в этом периоде были разработаны первые шкалы апатии, представляющие собой списки симптомов, каждый из которых психиатру следовало оценить с позиции того, насколько сильно он выражен у пациента. Как правило, эти шкалы апатии входили в обобщенные инструменты для диагностики ряда нейропсихиатрических симптомов под названием «уплощенный аффект» и были призваны оценивать снижение эмоциональности и спонтанности, отсутствие интонаций, физическую инертность, бедность лицевой экспрессии и коммуникативных жестов (Andreasen, 1984; Kay et al., 1987; Overall, Gorham, 1962). Типичным примером тестового пункта таких шкал апатии выступает симптом из Шкалы для оценки негативных симптомов (Scale for the Assessment of Negative Symptoms, SANS) H. Андреасена: «Снижение спонтанных движений. Пациент не демонстрирует ни одного либо показывает несколько спонтанных движений, не меняет позиции тела и конечностей» (Andreasen, 1984).

В 1990-х гг. американский психиатр Р. Марин высказал гипотезу о том, что апатия является потерей не эмоциональной чувствительности, а мотивации, в связи с чем может сопровождать широкий спектр психических, неврологических и соматических заболеваний (Marin et al., 1991). По сути, с этого момента наступил второй период психиатрических исследований апатии, главным итогом которого стала разработка общепризнанных диагностических критериев 
апатии, принятых в 2008 г. на консилиуме по проблемам диагностики апатии в рамках съезда Европейской психиатрической ассоциации (Robert et al., 2009).

Многие шкалы, созданные во втором периоде, опирались на так называемый золотой стандарт диагностики, согласно которому диагностическими критериями апатии являются такие признаки, как ослабление целенаправленного поведения, недостаток мотивации и снижение аффективного отклика. Например, один из тестовых пунктов в наиболее распространенной шкале этого периода - Шкале оценки апатии (Apathy Evaluation Scale, AES) P. Марина - звучит следующим образом: «Я заинтересован в получении нового опыта» (Marin et al., 1991).

Наконец, в 2014 г. шотландские исследователи Р. Радакович и С. Абрахамс опубликовали статью, в которой предложили новое понимание проблемы апатии как психического состояния, периодически появляющегося у большинства условно здоровых людей (Radakovic, Abrahams, 2014). Они разработали Многомерную шкалу апатии (Dimensional Apathy Scale, DAS) для диагностики эмоциональных («Я чувствую эмоциональную пустоту»), регуляторных («Иногда я начинаю какие-то дела, которые потом не могу закончить») и когнитивно-поведенческих («Мне трудно думать о том, что нужно делать») признаков апатии у условно здоровых респондентов. Спустя несколько лет их английские коллеги под руководством Ю. Анга разработали Индекс апатии и мотивации (Apathy Motivation Index, AMI), предназначенный для оценки поведенческой активации (способность к самостоятельному инициированию поведения), социальной мотивации (степень вовлеченности в социальные взаимодействия) и эмоциональной чувствительности (переживание позитивных и негативных привязанностей) (Ang et al., 2017).

Систематические психометрические обзоры, в том числе организованные посредством известного метода PRISMA (Preferred Reporting Items for Systematic Review and Meta-Analyses), показывают, что многие клинические шкалы являются валидными и надежными инструментами оценки апатии групп лиц с психоневрологическими заболеваниями (Radakovic et al., 2015). B то же время многомерные шкалы периодически ведут себя как гомогенные инструменты, что ставит под сомнение их психометрическую чувствительность к диагностике апатии у условно здоровых респондентов (GroenewegKoolhoven et al., 2016).

Между тем развитие идеи о нормальном состоянии апатии привело к тому, что в журналах психиатрического профиля стали публиковаться результаты исследований, опирающихся на психологические понятия и психологические инструменты диагностики. Эти исследования малочисленны, однако поднимают крайне важные вопросы о связи апатии, качества жизни и способов совладания с болезнью при боковом амиотрофическом склерозе, идиопатическом синдроме паркинсонизма, ВИЧ-инфекции и т.д. (Benito-Leyn et al., 2012; Kamat et al., 2016; Unglik et al., 2016).

Таким образом, современные специалисты отмечают движение проблемы апатии из психиатрии в психологию, которое первыми заметили и признали 
именно психиатры (Robert et al., 2009), они также фиксируют отсутствие психометрически обоснованных инструментов для диагностики апатии у условно здоровых респондентов (Groeneweg-Koolhoven et al., 2016). В связи с этим целью представленного исследования стала попытка разработки и психометрического анализа психологической шкалы апатии. Новая шкала ни в коей мере не претендует занять место существующих, проверенных временем клинических шкал, возможно, она станет дополнением к ним в психологических исследованиях апатии.

\section{Методика}

Участники исследования. В соответствии с классическими психометрическими стандартами каждый диагностический инструмент должен быть подвергнут как минимум трем процедурам, а именно оценке факторной структуры, базовых психометрических свойств и социальной желательности (Клайн, 1994). Общепризнанным также является тот факт, что для каждой процедуры исследователь должен сформировать отдельную группу респондентов с целью своевременной коррекции тестовых пунктов шкалы на соответствующих этапах ее психометрического анализа.

Исследование проводилось на трех выборках. Первая выборка была сформирована для оценки факторной структуры Шкалы апатии. Ее составили 114 сотрудников ФГБУ «Федеральный центр сердечно-сосудистой хирургии имени С.Г. Суханова» (г. Пермь) в возрасте от 21 года до 63 лет (среднее 36.29 , медиана - 35 лет; стандартное отклонение -8.87$)$, в том числе $16.7 \%$ мужчин и 83.3\% женщин со средним специальным (65.8\%) и высшим (34.2\%) образованием.

По данным второй выборки была осуществлена оценка надежности и валидности Шкалы апатии. В нее вошли 512 студентов различных вузов (г. Омск) в возрасте от 16 до 26 лет (среднее - 19.66, медиана - 20 лет; стандартное отклонение - 1.38), в том числе 46.8\% мужчин и 53.2\% женщин. Спустя месяц после тестирования 75 студентов повторно заполнили Шкалу апатии (отбор респондентов для оценки ретестовой надежности шкалы проводился на основе их согласия, отраженного в специальной графе при первом тестировании).

Третья выборка приняла участие в оценке социальной желательности Шкалы апатии. Ее составил 101 студент юридического вуза (г. Омск) в возрасте от 18 лет до 21 года (среднее - 19.8, медиана - 20 лет; стандартное отклонение - 0.77), в том числе $36.6 \%$ мужчин и $63.4 \%$ женщин.

Методики исследования. Первая выборка заполнила только пилотажную версию Шкалы апатии.

Для второй выборки был сформирован психодиагностический комплекс, в который помимо Шкалы апатии вошли следующие инструменты.

Краткая версия Опросника юношеской апатии Р. Хандельмана в адаптации А.А. Золотаревой предназначена для диагностики апатии в юношеском возрасте (Riconscente, 2007). Шкала содержит 10 тестовых пунктов, по отношению к 
которым респондент должен выразить свое согласие или несогласие по пятибалльной шкале Лайкерта (например, «Друзья считают меня пассивным») (Золотарева, 2018).

Шкала отчуждения от учебы Е.Н. Осина входит в состав Опросника субъективного отчуждения у учащихся (ОСОТЧ-У), разработанного как аналог теста С. Мадди и оценивающего различные формы отчуждения в таких сфеpax жизни, как общество, учеба, межличностные отношения, семья и собственная личность (Maddi, 1967). Шкала содержит 16 тестовых пунктов, оцениваемых с помощью пятибалльной шкалы Лайкерта, и диагностирует отношение студентов к предмету учебной деятельности (например, «Я не чувствую желания читать дополнительную литературу или ходить на факультативы») (Осин, 2015).

Опросник «Шкалы академической мотивации» Т.О. Гордеевой, О.А. Сычева и Е.Н. Осина соответствует формату студенческой версии Опросника академической мотивации (Academic Motivation Scale-College version, AMS-C) Р. Валлеранда (Vallerand et al., 1992). При заполнении русскоязычного опросника респондентам предлагается по пятибалльной шкале Лайкерта оценить различные ответы на вопрос «Почему вы в настоящее время ходите в университет?». Опросник содержит 28 тестовых пунктов, сгруппированных в семь шкал: «Познавательная мотивация» (например, «Мне интересно учиться»), «Мотивация достижения» (например, «Учеба доставляет мне удовольствие, я люблю решать трудные задачи»), «Мотивация саморазвития» (например, «Учеба дает мне возможность почувствовать удовлетворение в моем совершенствовании»), «Мотивация самоуважения» (например, «Потому что, когда я хорошо учусь, я чувствую себя значимым человеком»), «Интроецированная мотивация» (например, «Потому что совесть заставляет меня учиться»), «Экстернальная мотивация» (например, «У меня нет другого выбора, так как посещаемость отмечается»), и «Амотивация» (например, «Хожу по привычке, зачем, откровенно говоря, точно не знаю») (Гордеева и др., 2014).

Студенческая версия Утрехтской шкалы увлеченности работой В. Шауфелли (Utrecht Work Engagement Scale-Student Version, UWES-S) в адаптации Е.А. Ворониной, М.Л. Курьян и А.А. Шутова предназначена для диагностики увлеченности учебой как активного участия студентов в приобретении образования, сопровождаемого желанием и готовностью затрачивать ряд усилий, энергии и временны́х ресурсов на обучение (Schaufeli, Bakker, 2004). Русскоязычная версия шкалы содержит 14 тестовых пунктов с шестью вариантами ответов по шкале Лайкерта и оценивает показатели по трем субшкалам, или компонентам увлеченности учебой: «Энергичность» (например, «Когда я учусь, меня переполняет энергия»), «Энтузиазм» (например, «Моя учеба вдохновляет меня») и «Поглощенность» (например, «Во время учебы время пролетает незаметно») (Воронина и др., 2015).

Торонтская шкала алекситимии Р. Бэгби, Дж. Паркера и Дж. Тэйлора (Toronto Alexithymia Scale, TAS-20) в адаптации Е.Г. Старостиной и др. направлена на диагностику алекситимии как специфической черты личности, 
заключающейся в трудностях в определении и описании собственных чувств и чувств других людей (Bagby et al., 1994). Шкала включает 20 тестовых пунктов, оцениваемых по пятибалльной шкале Лайкерта и сгруппированных в три субшкалы: «Трудности в идентификации чувств» (например, «Мне трудно подбирать верные слова для своих чувств), «Трудности с описанием чувств другим людям» (например, «У меня бывают чувства, которые я не могу точно назвать») и «Внешне-ориентированный тип мышления» (например, «Я могу чувствовать близость к другому человеку, даже когда мы молчим») (Старостина и др., 2016).

Шкала социальной ангедонии М. Экбленда и Л. Чапмана (Revised Social Anhedonia Scale, RSAS) в адаптации O.В. Рычковой и А.Б. Холмогоровой предназначена для диагностики социальной ангедонии как дефицита способности к переживанию удовольствия от социальных контактов (Eckblad et al., 1982). Шкала представляет собой набор из 40 тестовых пунктов, каждый из которых респонденту в соответствии с инструкцией предлагается оценить в дихотомической шкале («верно» или «неверно»), и оценивает единый показатель социальной ангедонии (например, «Обычно я чувствую себя комфортно, только если я остаюсь один, размышляя или мечтая о чем-то») (Рычкова, Холмогорова, 2016).

Третья выборка приняла участие в экспериментальном методе оценки социальной желательности, который заключается в использовании техники на фальсификацию респондентами собственных ответов (Graham et al., 1991). Суть экспериментальной манипуляции состоит в том, что выборку исследования стратифицируют и случайным образом делят на три группы, одна из которых проходит тестирование со стандартной (или honesty - «честной») инструкцией, а две других - с так называемыми fake-good (в дословном переводе «притворись хорошим») и fake-bad («притворись плохим») инструкциями, в соответствии с которыми респондентов просят заполнить тест так, словно им нужно произвести хорошее или, наоборот, плохое впечатление на экспериментатора. Затем на основе результатов однофакторного дисперсионного анализа ANOVA исследователями делаются выводы об успешности проведенной экспериментальной манипуляции и социальной желательности оцениваемой шкалы.

Так, стратифицированная по полу третья выборка была распределена случайным образом на три группы, каждой из которых предъявлялась Шкала апатии с одной из трех инструкций: fake-good, стандартной или fake-bad. Стандартная инструкция звучала следующим образом: «Оцените, пожалуйста, свое согласие или несогласие с каждым суждением. Отвечайте как можно более искренне и помните, что не существует “хороших” и “плохих” ответов». Для fake-good и fake-bad инструкций были использованы следующие формулировки инструкции: «Представьте, что вам нужно произвести хорошее/плохое впечатление. Оцените, пожалуйста, свое согласие или несогласие с каждым суждением с позиции “хорошего/плохого” человека».

Респонденты из третьей выборки также заполнили Шкалу управления впечатлениями из Опросника социальной желательности Д. Паулуса в адаптации 
Е.Н. Осина со стандартной инструкцией (Осин, 2011). Данная шкала содержит 15 тестовых пунктов с семибалльной шкалой Лайкерта для оценок, представляет собой русскоязычную версию шкалы «Impression Management» из широко применяемой в исследованиях социальной желательности англоязычной методики Balanced Inventory of Desirable Responding (BIDR) и предназначена для измерения сознательного искажения ответов (например, «Когда я слышу личную беседу двух людей, я стараюсь не прислушиваться») (Paulhus, 1998).

\section{Результаты}

Разработка тестовых пунктов. Анализ психологической литературы позволил определить апатию как психическое состояние, характеризующееся безразличием по отношению к себе, другим и миру, и выделить 30 психометрических дескрипторов апатии (например, «безнадежность», «грусть», «косность», «лень», «пассивность», «опустошенность», «равнодушие», «скука», «тоска» и т.д.). Далее психометрические дескрипторы апатии были определены с помощью толкового словаря русского языка Д.Н. Ушакова (Ушаков, 2005) и благодаря последнему операционализированы в тестовые пункты (дескриптору «безнадежность» соответствовал тестовый пункт «Я убежден, что любые попытки изменить мир тщетны», дескриптору «грусть» - «Иногда я грущу без повода» и т.д.). Для собранной из тестовых пунктов пилотажной версии Шкалы апатии была сформулирована следующая инструкция: Щеред вами набор суждений о различных мыслях и чувствах, которые периодически испытывают многие люди. Оцените, пожалуйста, насколько верно данные суждения отражают ваше состояние на протяжении прошедшего месяца, используя следующую шкалу: 1 = не согласен; 2 = скорее не согласен; 3 = скорее согласен; 4 = согласен».

Предварительная апробация. В ходе предварительной апробации Шкалы апатии из нее были исключены «неэффективные» тестовые пункты, к которым традиционно относятся пункты с малым разбросом и существенными асимметриями распределения (Батурин, Мельникова, 2009). В результате апробации было отобрано 12 «эффективных» тестовых пунктов.

Анализ внутренней согласованности шкалы был реализован, во-первых, с помощью вычисления коэффициента внутренней согласованности $\alpha$ Кронбаха ( $\alpha$ составила 0.85), во-вторых, с помощью анализа матрицы интеркорреляций для тестовых пунктов, который также подтвердил гомогенность шкалы (все значения коэффициентов корреляции между каждым тестовым пунктом и суммой оставшихся пунктов достигли величины 0.5, а диапазон коэффициентов интеркорреляций составил значения от 0.2 до 0.6). Таким образом, установлено, что гомогенная структура Шкалы апатии полностью соответствует психометрическим требованиям, предъявляемым к внутренней согласованности (по мнению разных специалистов, значения должны варьироваться в пределах от 0.7 до 0.9), а также так называемым показателям «item-total correlations» (корреляции между пунктом и шкалой, значения которых должны превышать показатель 0.3) и «inter-item correlations» (интеркорреляции для 
тестовых пунктов, показатели которых должны варьироваться в диапазоне от 0.2 до 0.5) (DeVellis, 2003).

В психометрической практике наряду с проверкой внутренней согласованности шкалы принято оценивать ее дискриминативность с помощью коэффициента $\delta$ Фергюсона. Для Шкалы апатии данный показатель составил 0.97, т.е. превысил классический психометрический стандарт, равный 0.9 (Ferguson, 1949).

Факторная структура. В соответствии с тем что Шкала апатии изначально разрабатывалась как гомогенная, проверке подлежала модель, в которой все тестовые пункты входили в один общий фактор. Для оценки факторной структуры шкалы был использован конфирматорный факторный анализ. Проверяемая модель продемонстрировала приемлемый уровень соответствия данным (Satorra-Bentler $\chi^{2}(59)=44.18, p=0.924$; CFI $=0.940$; RMSEA $=0.000$ $(90 \%$ CI от 0.000 до 0.020), SRMR $=0.065)$. Факторная структура шкалы оказалась практически идеальной с точки зрения общепризнанных критериев $(\mathrm{RMSEA} \leqslant 0.06 ; \mathrm{CFI} \leqslant 0.95 ; \mathrm{SRMR} \leqslant 0.08)$ (Hu, Bentler, 1999). Исключение составил показатель CFI, однако многие авторы полагают, что им можно пренебречь при условии, если величина $\chi^{2}$ незначима $(p>0.05)$ и при делении на степени свободы не зависит от размера выборки $\left(\chi^{2} / \mathrm{df} \leqslant 3\right)$ (Marsh et al., 2004). На рисунке 1 представлена факторная структура Шкалы апатии.

Надежность и валидность. Надежность шкалы вычислялась с помощью метода Бланда-Альтмана. На рисунке 2 показано, что средние значения апатии, измеренной во время теста $(\mathrm{M}=26.91, \mathrm{SD}=6.56)$ и ретеста $(\mathrm{M}=26.39$,

\section{Факторная структура Шкалы апатии}

Рисунок 1

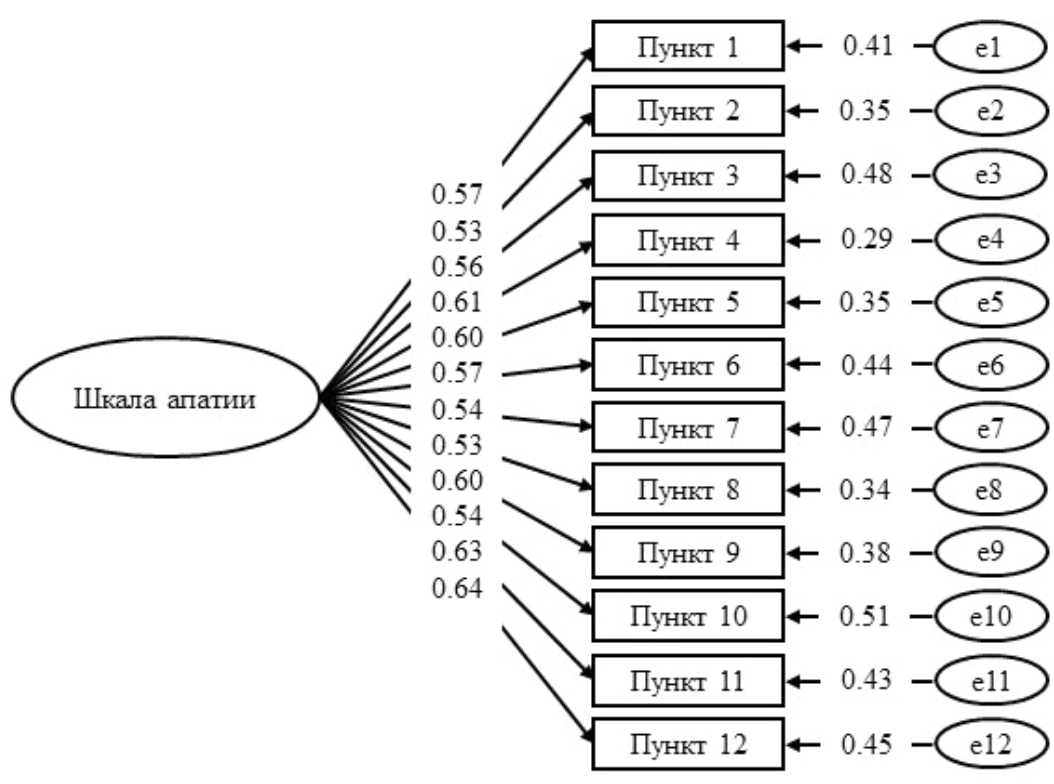


Рисунок 2

Показатели ретестовой надежности Шкалы апатии по графику Бланда-Альтмана

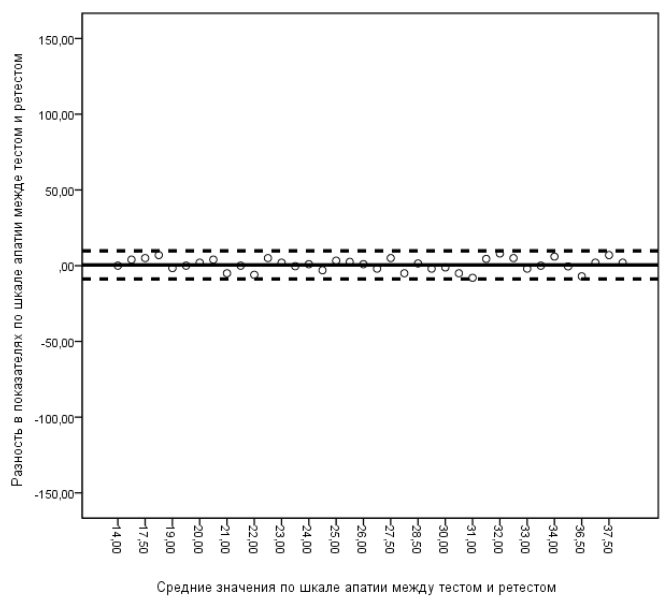

$\mathrm{SD}=6.56)$, оказались схожими, а различия между ними - статистически не значимыми $(\mathrm{t}=0.95$ при р $>0.05 ; 95 \%$ CI $[-0.57 ; 1.61])$, что свидетельствует о ретестовой надежности Шкалы апатии.

Корреляционные связи между Шкалой апатии и другими шкалами обнаружили прогнозируемые закономерности. Как и ожидалось, при проведении опроса в студенческой среде Шкала апатии демонстрирует тесные прямые связи с показателями юношеской апатии, отчуждения от учебы, академической амотивации, трудностей в идентификации чувств и сложностей с описанием чувств другим людям, социальной ангедонии, а также умеренные обратные связи с показателями вовлеченности в учебу и шкалами внутренней и внешней академической мотивации. Единственным показателем, с которым апатия не обнаружила значимой корреляционной связи, оказался внешне-ориентированный тип мышления (подробные сведения приведены в таблице 1). В целом обнаруженные корреляционные связи свидетельствуют в пользу конвергентной и дивергентной валидности шкалы.

Социальная желательность. Для проверки успешности экспериментальной манипуляции с инструкциями к Шкале апатии был проведен однофакторный дисперсионный анализ ANOVA, результаты которого указывают на то, что между группами респондентов, заполнивших шкалу с различными инструкциями, существуют значимые различия в степени выраженности апатии $(\mathrm{F}(2,98)=158.37, p<0.001)$ (значения средних и стандартных отклонений для всех групп респондентов представлены в таблице 2).

Апостериорный анализ по методу Тьюки показал, что участники со стандартной инструкцией набрали более низкие баллы по Шкале апатии, нежели участники c fake-good инструкцией $($ ТРНT $=6.98, p<0.001)$, и более высокие по сравнению с участниками с fake-bad инструкцией $(\mathrm{TPHT}=17.49, p<0.001)$. Соответственно респонденты c fake-good инструкцией набрали значимо более 
Таблица 1

Корреляционные связи (по методу Спирмена) между Шкалой апатии и другими шкалами

\begin{tabular}{|c|c|}
\hline Переменные & Апатия \\
\hline Юношеская апатия $(\mathrm{N}=346)$ & $0.48^{* * *}$ \\
\hline Отчуждение от учебы $(\mathrm{N}=346)$ & $0.57 * * *$ \\
\hline \multicolumn{2}{|l|}{ Академическая мотивация (N = 346) } \\
\hline Познавательная мотивация & $-0.43^{* * *}$ \\
\hline Мотивация достижения & $-0.32 * * *$ \\
\hline Мотивация саморазвития & $-0.48 * * *$ \\
\hline Мотивация самоуважения & $-0.27^{* * *}$ \\
\hline Интроецированная мотивация & $-0.14^{* *}$ \\
\hline Экстернальная мотивация & $-0.12^{*}$ \\
\hline Амотивация & $0.46^{* * *}$ \\
\hline \multicolumn{2}{|l|}{ Увлеченность учебой $(\mathrm{N}=346)$} \\
\hline Энергичность & $-0.17^{* *}$ \\
\hline Энтузиазм & $-0.34^{* * *}$ \\
\hline Поглощенность & $-0.13^{*}$ \\
\hline \multicolumn{2}{|l|}{ Алекситимия $(\mathrm{N}=166)$} \\
\hline Трудности в идентификации чувств & $0.55^{* * *}$ \\
\hline Трудности с описанием чувств другим людям & $0.44^{* * *}$ \\
\hline Внешне-ориентированный тип мышления & 0.11 \\
\hline Социальная ангедония $(\mathrm{N}=166)$ & $0.29 * * *$ \\
\hline
\end{tabular}

${ }^{*} p<0.05,{ }^{* * *} p<0.01,{ }^{* * *} p<0.001$.

Таблица 2

Описательная статистика для Шкалы апатии в условиях fake-good, стандартной и fake-bad инструкций

\begin{tabular}{|c|c|c|c|}
\hline & $\begin{array}{c}\text { Fake-good } \\
\text { инструкция M (SD) }\end{array}$ & $\begin{array}{c}\text { Стандартная } \\
\text { инструкция M (SD) }\end{array}$ & $\begin{array}{c}\text { Fake-bad инструкция } \\
\text { M (SD) }\end{array}$ \\
\hline Шкала апатии & $18.30(6.30)$ & $25.27(5.34)$ & $42.77(5.82)$ \\
\hline
\end{tabular}

высокие показатели по Шкале апатии, чем участники c fake-bad инструкцией $(\mathrm{TPHT}=24.47, p<0.001)$. Данные различия графически продемонстрированы на рисунке 3.

Кроме того, между показателями по Шкале апатии и Шкале управления впечатлениями из Опросника социальной желательности не было обнаружено значимых корреляционных связей ни в условиях fake-good ( $\mathrm{r}=-0.17, p>0.05)$, 
Различия в показателях апатии между респондентами в условиях fake-good, стандартной и fake-bad инструкций

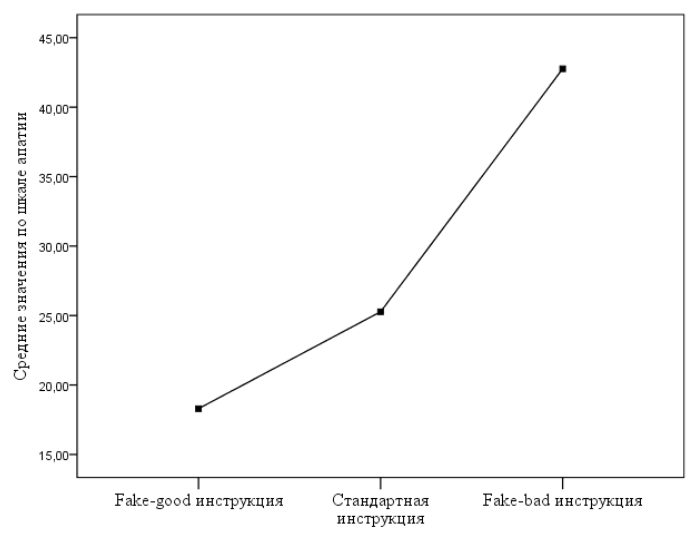

ни в условиях стандартной $(r=-0.09, p>0.05)$, ни в условиях fake-bad $(r=0.09$, $p>0.05)$ инструкций.

\section{Обсуждение результатов}

Основным результатом проведенного исследования стал психометрический анализ Шкалы апатии. В частности, анализ базовых психометрических свойств (факторной структуры, внутренней согласованности, показателей «item-total correlations» и «inter-item correlations») указал на гомогенную факторную структуру шкалы. Полученный результат противоречит последним тенденциям в практике психиатрических исследований, согласно которым апатию принято рассматривать как сложный, многокомпонентный феномен (Radakovic et al., 2016), однако согласуется с данными о том, что в популяции условно здоровых лиц любые шкалы апатии ведут себя как гомогенные диагностические инструменты (Groeneweg-Koolhoven et al., 2016).

Для валидизации Шкалы апатии были выбраны инструменты, направленные на диагностику связанных с учебной деятельностью характеристик и состояний. В зарубежных публикациях можно встретить ряд исследований, в которых показано, что апатичные студенты испытывают трудности с усвоением образовательной программы (Larson, 2000), тяжело налаживают социальные контакты с однокурсниками (Bjornsen et al., 2007), имеют слабую академическую мотивацию (Powell, 2005), высказывают мысли о собственной беспомощности (Campling, 2002), ощущают себя психологически изолированными от учебного процесса (Lee et al., 2001) и т.д. Кроме того, по сведениям зарубежных исследователей, апатия тесно связана с алекситимией (Ready et al., 2016) и социальной ангедонией (Husain, Roiser, 2018). Эти данные полностью согласуются с обнаруженными закономерностями и свидетельствуют в пользу конвергентной и дивергентной валидности Шкалы апатии. 
Показатели ретестовой надежности также позволяют считать шкалу стабильным во времени психодиагностическим инструментом, способным с высокой точностью определять динамику апатии в условно здоровой популяции.

Очевидным ограничением оценки валидности Шкалы апатии является кросс-секционный характер исследования, в соответствии с которым можно лишь констатировать наличие или отсутствие определенных закономерностей, но нельзя сделать вывод об их причинах и следствиях. Тем самым одной из первоочередных научных перспектив в отношении разработанной шкалы должна быть оценка ее прогностической валидности. Зарубежные психиатрические шкалы апатии показали прогностические способности в оценке времени пребывания пожилых лиц в стационаре (Resnick et al., 1998), работоспособности и успешности социальных навыков (Overall, Gorham, 1962), профессиональной мотивации и качества выполняемых работ в группах лиц с психоневрологическими заболеваниями (Каy et al., 1987). Соответственно для оценки прогностической валидности психологической Шкалы апатии в условно здоровой популяции нужны критерии, лежащие в поле возможных психологических последствий апатии (например, академическая успеваемость, спортивные достижения и т.д.).

Наконец, согласно полученным в рамках исследования результатам, Шкала апатии обладает устойчивостью по отношению к эффектам социальной желательности. Эта закономерность распространяется на случаи как позитивной, так и негативной фальсификации результатов диагностики апатии. В отличие от большинства социально желанных феноменов, подвергаемых оценке риска позитивной фальсификации, апатия, с одной стороны, относится к социально неодобряемым явлениям, а с другой стороны, в ряде случаев может быть выгодной для респондента.

Так, если в психодиагностических ситуациях профессиональной или принудительной клинической психодиагностики респондент будет склонен снижать собственные оценки апатии, то в ситуациях самостоятельного обращения за профессиональной психиатрической и психологической помощью, а также при прогнозировании практической выгоды (например, при желании фальсифицировать тяжесть собственных психических расстройств у лиц, призванных на военную службу), напротив, следует ожидать завышенные показатели апатии. Однако тот факт, что Шкала апатии показала устойчивость по отношению к рискам фальсификации, свидетельствует о ее потенциальной адекватности в условиях даже высокой социальной желательности. Это свойство новой шкалы является несомненным психометрическим достоинством с учетом того, что апатия рассматривается исследователями как подверженный социальной желательности феномен (Hampson et al., 1987).

Критическим моментом выступает тот факт, что показатели апатии протестированных респондентов не измерялись до экспериментальной манипуляции, в связи с чем остается открытым вопрос о смещении баллов по Шкале апатии в условиях стандартной инструкции и инструкций на позитивную и негативную фальсификацию результатов тестирования. Этот момент имеет важное практическое значение, поскольку знание того, насколько сильно 
отличаются аутентичные и симулированные показатели одного и того же респондента по той или иной шкале, позволяет специалистам прогнозировать достоверность результатов тестирования в различных психодиагностических ситуациях (Smith, 1974). Идеальная научная перспектива в этом плане заключается в оценке социальной желательности с помощью новых методов исследования, например, с привлечением экспертной оценки или измерением латентного периода перед выдачей ответа респондентом.

\section{Заключение}

В описанном исследовании собраны доказательства психометрической состоятельности Шкалы апатии. Основные результаты сводятся к тому, что разработанная шкала обладает, по крайней мере, несколькими эффективными психометрическими показателями, а именно: 1) гомогенной и воспроизводимой факторной структурой; 2) надежностью и валидностью (конвергентной в силу прямых связей с показателями юношеской апатии, отчуждения от учебы, академической амотивации, алекситимии и социальной ангедонии, а также дивергентной - в силу обратных связей с показателями увлеченности учебой, внутренней и внешней академической мотивации); 3) устойчивостью и адекватностью в условиях социальной желательности. Эти психометрические показатели являются базовыми и потому, несмотря на ранее изложенные ограничения и перспективы исследования, позволяют говорить о том, что Шкала апатии является надежным и валидным инструментом для психологической диагностики апатии у условно здоровых респондентов.

\section{Литература}

Батурин, Н. А., Мельникова, Н. Н. (2009). Технология разработки тестов: часть II. Вестник Южно-Уральского государственного университета. Серия «Психология», 175(42), 11-25.

Воронина, Е. А., Курьян, М. Л., Шутов, А. А. (2015). Диагностика увлеченности учебой как элемент «студентоцентрированного» образования. Вестник НГТУ им. Р.Е. Алексеева. Серия «Управление в социальных системах. Коммуникативные технологии», 2, 59-66.

Гордеева, Т. О., Сычев, О. А., Осин, Е. Н. (2014). Опросник «Шкалы академической мотивации». Психологический журнал, 35(4), 96-107.

Золотарева, А. А. (2018). Русскоязычная версия опросника юношеской апатии Р. Хандельмана. Психологическая наука и образование, 23(6), 16-24. doi:10.17759/pse.2018230602

Клайн, П. (1994). Справочное руководство по конструированию тестов. Киев: ПАН ЛТД.

Осин, Е. Н. (2011). Проблема социальной желательности в исследованиях личностного потенциала. В кн. Д. А. Леонтьев (ред.), Личностный потенциал: структура и диагностика (с. 454468). М.: Смысл.

Осин, Е. Н. (2015). Отчуждение от учебы как предиктор выгорания у студентов вузов: роль характеристик образовательной среды. Психологическая наука и образование, 20(4), 57-74. doi:10.17759/pse.2015200406 
Рычкова, О. В., Холмогорова, А. Б. (2016). Адаптация методики диагностики социальной ангедонии (RSAS) на российской выборке. Консультативная психология и психотерапия, 24(4), 62-96. doi:10.17759/cpp20162404004

Старостина, Е. Г., Тэйлор, Г. Дж., Квилти, Л. К., Бобров, А. Е., Мошняга, Е. Н., Пузырева, Н. В., ... Бэгби, М. (2010). Торонтская шкала алекситимии (20 пунктов): валидизация русскоязычной версии на выборке терапевтических больных. Социальная и клиническая психиатрия, 20(4), 31-38.

Ушаков, Д. Н. (2005). Толковый словарь русского языка. М.: Альта-Принт.

Ссылки на зарубежные источники см. в разделе References после англоязычного блока.

Приложение

\section{Шкала апатии}

Инструкция. Перед вами набор суждений о различных мыслях и чувствах, которые периодические испытывают многие люди. Оцените, пожалуйста, насколько верно данные суждения отражают ваше состояние на протяжении прошедшего месяца, используя следующую шкалу:

\begin{tabular}{|c|c|c|c|}
\hline 1 & 2 & 3 & 4 \\
\hline Не согласен & Скорее не согласен & Скорее согласен & Согласен \\
\hline
\end{tabular}

\begin{tabular}{|c|l|c|c|c|c|}
\hline 1. & Я убежден, что любые попытки изменить мир тщетны & 1 & 2 & 3 & 4 \\
\hline 2. & В моей жизни бывают периоды, когда я остаюсь ко всему безучастным & 1 & 2 & 3 & 4 \\
\hline 3. & Свое нынешнее состояние я могу назвать упадком сил & 1 & 2 & 3 & 4 \\
\hline 4. & $\begin{array}{l}\text { Мне стало лень заниматься делами, которые раньше вызывали у меня } \\
\text { интерес }\end{array}$ & 1 & 2 & 3 & 4 \\
\hline 5. & Иногда я не чувствую вкуса жизни & 1 & 2 & 3 & 4 \\
\hline 6. & Я фаталист и считаю, что человек бессилен против судьбы & 1 & 2 & 3 & 4 \\
\hline 7. & $\begin{array}{l}\text { По возможности я стараюсь дистанцироваться от сильных чувств и } \\
\text { переживаний }\end{array}$ & 1 & 2 & 3 & 4 \\
\hline 8. & Мне знакомо состояние, когда находишься на грани отчаяния & 1 & 2 & 3 & 4 \\
\hline 9. & Никому нет дела до моих проблем и жизненных неурядиц & 1 & 2 & 3 & 4 \\
\hline 10. & $\begin{array}{l}\text { Ко многим предметам, которыми восторгаются другие, я испытываю } \\
\text { равнодушие }\end{array}$ & 1 & 2 & 3 & 4 \\
\hline 11. & С некоторых пор я стал редко общаться с близкими мне людьми & 1 & 2 & 3 & 4 \\
\hline 12. & $\begin{array}{l}\text { Я довольно прохладно отношусь к любой идее совершенствования себя или } \\
\text { мира }\end{array}$ & 1 & 2 & 3 & 4 \\
\hline
\end{tabular}


Обработка результатов. Для оценки показателя апатии необходимо суммировать значения по всем тестовым пунктам $(1=$ «не согласен», $2=$ «скорее не согласен», $3=$ «скорее согласен», 4 = «согласен»).

Тестовые нормы для первых двух выборок исследования ( $=626$; данные респондентов из третьей выборки не учитывались в силу экспериментальных манипуляций с инструкциями) получились следующими: 17 и менее баллов - низкий уровень апатии; от 18 до 31 балла - средний уровень апатии; 32 и более баллов - высокий уровень апатии.

Золотарева Алена Анатольевна - научный сотрудник, Международная лаборатория позитивной психологии личности и мотивации, Национальный исследовательский университет «Высшая школа экономики», кандидат психологических наук.

Сфера научных интересов: психология личности, психодиагностика, психометрика.

Контакты: alena.a.zolotareva@gmail.com 


\title{
Psychometric Analysis of the New Apathy Scale
}

\author{
A.A. Zolotareva \\ ${ }^{a}$ National Research University Higher School of Economics, 20 Myasnitskaya Str., Moscow, 101000, \\ Russian Federation
}

\begin{abstract}
The article presents the results of the development and psychometric analysis of the new psychological Apathy Scale. In three consecutive studies, in which a total of 727 adult Russian-speaking respondents took part, convincing evidence of psychometric consistency of the scale was obtained. In the first study, a preliminary approbation of the Apathy Scale was done, which indicated a homogeneous and reproducible factor structure of the scale. In the second study, the reliability and validity of the Apathy Scale was evaluated. The Cronbach's alpha coefficient was 0.85 , and the differences between the mean apathy values measured during the test and retest were not statistically significant according to the Bland-Altman plot. Convergent and divergent validity of the scale was established by means of positive correlations of the scale with indicators of adolescent apathy, alienation from study, academic amotivation, alexithymia and social anhedonia, as well as negative correlations with indicators of student engagement, intrinsic cognition, achievement, personal growth, motivation for self-respect, introjected motivation and external regulation. The third study assessed the social desirability of the Apathy Scale. With the help of experimental manipulation with fake-good, standard and fake-bad instructions, as well as the analysis of correlations of the scale with the Paulhus' Balanced Inventory of Desirable Responding, it was shown that the scale is stable and adequate in conditions of high social desirability. Based on the results of the study, it is concluded that the new psychological Apathy Scale is a reliable and valid instrument for the psychological assessment of apathy in adult Russian-speaking respondents.
\end{abstract}

Keywords: apathy, Apathy Scale, factor structure, reliability, validity, social desirability.

\section{References}

Andreasen, N. C. (1984). Scale for the Assessment of Negative Symptoms (SANS). Iowa City, IA: University of Iowa.

Ang, Y. S., Lockwood, P., Apps, M. A., Muhammed, K., \& Husain, M. (2017). Distinct subtypes of apathy revealed by the Apathy-Motivation Index. PLoS ONE, 12(1), e0169938. doi:10.1371/journal.pone.0169938

Bagby, R. M., Parker, J. D., \& Taylor, G. J. (1994). The twenty-item Toronto Alexithymia Scale - I. Item selection and cross-validation of the factor structure. Journal of Psychosomatic Research, 38(1), 23-32. doi:10.1016/0022-3999(94)90005-1

Baturin, N. A., \& Mel'nikova, N. N. (2009). Tekhnologiya razrabotki testov: chast' II [The technology of test development: Part II]. Vestnik Yuzhno-Ural'skogo Gosudarstvennogo Universiteta. Series "Psychology", 175(42), 11-25. (in Russian) 
Benito-Leyn, J., Cubo, E., Coronell, C., \& ANIMO Study Group. (2012). Impact of apathy on healthrelated quality of life in recently diagnosed Parkinson's disease: the ANIMO study. Movement Disorders, 27(2), 211-218. doi:10.1002/mds.23872

Bjornsen, C. A., Scepansky, J. A., \& Suzuki, A. (2007). Apathy and personality traits among college students: A cross-cultural comparison. College Student Journal, 41(3), 668-675.

Bleuler, E. (1911). Dementia praecox, or the group of schizophrenias. New York: International Universities Press.

Campling, P. (2002). Connection and catastrophe, hope and despair in our border-line world. British Journal of Psychotherapy, 19(2), 235-245. doi:10.1111/j.1752-0118.2002.tb00076.x

Clarke, D. E., Ko, J. Y., Kuhl, E. A., van Reekum, R., Salvador, R., \& Marin, R. S. (2011). Are the available apathy measures reliable and valid? Journal of Psychosomatic Research, 70(1), 73-93. doi:10.1016/j.ipsychores.2010.01.012

DeVellis, R. F. (2003). Scale development: theory and applications (2nd ed.). Thousand Oaks, CA: Sage Publications.

Eckblad, M. L., Chapman, L. J., Chapman, J. P., \& Mischlove, M. (1982). The Revised Social Anhedonia Scale (Unpublished test). Available from L. J. Chapman, University of Wisconsin, Madison, WI.

Ferguson, G. A. (1949). On the theory of test discrimination. Psychometrika, 14(1), 61-68. doi:10.1007/BF02290141

Gordeeva, T. O., Sychev, O. A., \& Osin, E. N. (2014). "Academic motivation scales" questionnaire. Psikhologicheskii Zhurnal, 35(4), 96-107. (in Russian)

Graham, J. R., Watts, D., \& Timbrook, R. E. (1991). Detecting fake-good and fake-bad MMPI-2 profiles. Journal of Personality Assessment, 57(2), 264-277. doi:10.1207/s15327752jpa5702_6

Groeneweg-Koolhoven, I., Huitema, L. J., de Waal, M. W. M., \& Rhebergen, D. (2016). Latent class analysis of the Apathy Scale does not identify subtypes of apathy in general population-based older persons. International Journal of Geriatric Psychiatry, 31(9), 1021-1028. doi:10.1002/gps.4413

Hampson, S. E., Goldberg, L. R., \& John, O. P. (1987). Category-breadth and social-desirability values for 573 personality terms. European Journal of Personality, 1, 241-258. doi:10.1002/per.2410010405

Handelman, R. (1999). Defining and assessing adolescent apathy. New York: City University of New York.

Hu, L., \& Bentler, P. M. (1999). Cutoff criteria for fit indexes in covariance structure analysis: Conventional criteria versus new alternatives. Structural Equation Modeling, 6, 1-55. doi:10.1080/10705519909540118

Husain, M., \& Roiser, J. P. (2018). Neuroscience of apathy and anhedonia: A transdiagnostic approach. Nature Reviewes Neurosciences, 19(8), 470-484. doi:10.1038/s41583-018-0029-9

Kamat, R., Woods, S. P., Cameron, M. V., \& Iudicello, J. E. (2016). Apathy is associated with lower mental and physical quality of life in persons infected with HIV. Psychology, Health and Medicine, 21(7), 890-901. doi:10.1080/13548506.2015.1131998

Kay, S. R., Fiszbein, A., \& Opler, L. A. (1987). The Positive and Negative Syndrome Scale (PANSS) for schizophrenia. Schizophrenia Bulletin, 13(2), 261-276. doi:10.1093/schbul/13.2.261

Kline, P. (1994). Spravochnoe rukovodstvo po konstruirovaniyu testov [A handbook of test construction]. Kiev: PAN LTD. (in Russian; transl. of: Kline, P. (1986). A handbook of test construction: Introduction to psychometric design. London: Methuen.)

Kraepelin, E. (1919). Dementia praecox and paraphrenia. Edinburgh: Livingstone.

Larson, R. W. (2000). Toward a psychology of positive youth development. American Psychologist, 55(1), 170-183. doi:10.1037//0003-066X.55.1.170 
Lee, R. M., Draper, M., \& Lee, S. (2001). Social connectedness, dysfunctional interpersonal behaviors, and psychological distress: Testing a mediator model. Journal of Counseling Psychology, 48(3), 310-318. doi:10.1037/0022-0167.48.3.310

Maddi, S. R. (1967). The existential neurosis. Journal of Abnormal Psychology, 72(4), 311-325. doi:10.1037/h0020103

Marin, R. S., Biedrzycki, R. C., \& Firinciogullari, S. (1991). Reliability and validity of the Apathy Evaluation Scale. Psychiatry Research, 38(2), 143-162. doi:10.1016/0165-1781(91)900040-v

Marsh, H. W., Hau, K. T., \& Wen, Z. (2004). In search of golden rules: Comment on hypothesis-testing approaches to setting cutoff values for fit indexes and dangers in overgeneralizing Hu and Bentler's (1999) findings. Structural Equation Modeling, 11(3), 320-341.doi:10.1207/s15328007sem1103_2

Masselon, R. (1902). Psychologie des dements precoces. Paris: Thuse de Paris. (in French)

Osin, E. N. (2011). Problema sotsial'noi zhelatel'nosti v issledovaniyakh lichnostnogo potentsiala [The issue of social desirability in studies on personality potential]. In D. A. Leontiev (Ed.), Lichnostnyi potentsial: struktura i diagnostika [Personality potential: Structure and diagnostics] (pp. 454-468). Moscow: Smysl. (in Russian)

Osin, E. N. (2015). Alienation from study as a predictor of burnout in university students: the role of the educational environment characteristics. Psikhologicheskaya Nauka i Obrazovanie [Psychological Science and Education], 20(4), 57-74. (in Russian)

Overall, J. E., \& Gorham, D. R. (1962). The Brief Psychiatric Rating Scale. Psychological Reports, 10, 799-812.

Paulhus, D. L. (1998). Manual for the Balanced Inventory of Desirable Responding. Toronto, ON: Multi-Health Systems.

Powell, S. (2005). Apathy and attitude: A study of motivation in Japanese high school students of English. Asian Englishes, 8(2), 46-63. doi:10.1080/13488678.2005.10801166

Radakovic, R., \& Abrahams, S. (2014). Developing a new apathy measurement scale: Dimensional Apathy Scale. Psychiatry Research, 219(3), 658-663. doi:10.1016/j.psychres.2014.06.010

Radakovic, R., Harley, C., Abrahams, S., \& Starr, J. M. (2015). A systematic review of the validity and reliability of apathy scales in neurodegenerative conditions. International Psychogeriatrics, 27(6), 903-923. doi:10.1017/S1041610214002221

Radakovic, R., Stephenson, L., Colville, S., Swingler, R., Chandran, S., \& Abrahams, S. (2016). Multidimensional apathy in ALS: Validation of the Dimensional Apathy Scale. Journal of Neurology, Neurosurgery, and Psychiatry, 87(6), 663-669. doi:10.1136/jnnp-2015-310772

Ready, R. E., Mather, M. A., Santorelli, G. D., \& Santospago, B. P. (2016). Apathy, alexithymia, and depressive symptoms: Points of convergence and divergence. Psychiatry Research, 244, 306-311. doi:10.1016/j.psychres.2016.07.046

Resnick, B., Zimmerman, S. I., Magaziner, J., \& Adelman, A. (1998). Use of the Apathy Evaluation Scale as a measure of motivation in elderly people. Rehabilitation Nursing, 23(3), 141-147. doi:10.1002/j.2048-7940.1998.tb01766.x

Riconscente, M. M. (2007). School-related apathy in 8th- and 10th- grade students: A mixed method exploration of definitions, construct independence, correlates, and grade-level differences. Dissertation Abstracts International, 68(4-A), 1329.

Robert, P. H., Onyike, C. U., Leentjens, A. F., Dujardin, K., Aalten, P., Starkstein, S., ... Byrne, J. (2009). Proposed diagnostic criteria for apathy in Alzheimer's disease and other neuropsychiatric disorders. European Psychiatry, 24(2), 98-104. doi:10.1016/j.eurpsy.2008.09.001 
Rychkova, O. V., \& Kholmogorova, A. B. (2016). Adaptation of Revised Social Anhedonia Scale (RSAS) on Russian sample. Konsul'tationaya Psikhologiya i Psikhoterapiya [Counseling Psychology and Psychotherapy], 24(4), 62-96. (in Russian)

Schaufeli, W. B., \& Bakker, A. B. (2004). Test manual for the Utrecht Work Engagement Scale (Unpublished manuscript). Utrecht University, The Netherlands.

Smith, R. C. (1974). Response bias in the State-Trait Anxiety Inventory: Detecting the exaggeration of stress. Journal of Psychology, 86(2), 241-246. doi:10.1080/00223980.1974.9924823

Starostina, E. G., Taylor, G. D., Quilty, L., Bobrov, A. E., Moshnyaga, E. N., Puzyreva, N. V., ... Bagby, M. (2010). A new 20-item version of the Toronto Alexithymia Scale: Validation of the Russian language translation in a sample of medical patients. Sotsial'naya i Klinicheskaya Psikhiatriya, 20(4), 31-38. (in Russian)

Unglik, J., Bungener, C., Delgadillo, D., Salachas, F., Pradat, P. F., Bruneteau, G., ... Lacomblez, L. (2016). Emotional feeling, coping strategies and apathy in amyotrophic lateral sclerosis. Annals of Neurodegenerative Disorders, 1(4), 1019.

Ushakov, D. N. (2005). Tolkovyi slovar' russkogo yazyka [The explanatory dictionary of Russian language]. Moscow: Al'ta-Print. (in Russian)

Vallerand, R. J., Pelletier, L. G., Blais, M. R., Brière, N. M., Senécal, C., \& Vallières, E. F. (1992). The Academic Motivation Scale: A measure of intrinsic, extrinsic, and amotivation in education. Educational and Psychological Measurement, 52, 1003-1017. doi:10.1177/00131644492052004025

Voronina, E. A., Kur'yan, M. L., \& Shutov, A. A. (2015). Diagnostika uvlechennosti ucheboi kak element «studentotsentrirovannogo» obrazovaniya [Diagnostics of engagement with studies as an element of student-oriented education]. Vestnik NGTU im. R.E. Alekseeva. Series "Upravlenie v sotsial'nykh sistemakh. Kommunikativnye tekhnologii”, 2, 59-66. (in Russian)

Zolotareva, A. A. (2018). Russian version of the Handelman's Adolescent Apathy Inventory. Psikhologicheskaya Nauka i Obrazovanie [Psychological Science and Education], 23(6), 16-24. (in Russian)

Alena A. Zolotareva - Research Fellow, International laboratory of positive psychology of personality and motivation, National Research University Higher School of Economics, PhD in Psychology.

Research area: psychology of personality, psychological assessment, psychometrics.

E-mail: alena.a.zolotareva@gmail.com 